Article

\title{
Low-Carbon Transformation of Electric System against Power Shortage in China: Policy Optimization
}

\author{
Bo Wang ${ }^{1,2}$, Limao Wang ${ }^{1,2, *}$, Shuai Zhong ${ }^{1,2, *}$, Ning Xiang ${ }^{1,2}{ }^{(1)}$ and Qiushi Qu ${ }^{3}$ \\ 1 Institute of Geographic Sciences and Natural Resources Research, Chinese Academy of Sciences, \\ Beijing 100101, China; wangb.19b@igsnrr.ac.cn (B.W.); xiangn.18b@igsnrr.ac.cn (N.X.) \\ 2 College of Resources and Environment, University of Chinese Academy of Sciences, Beijing 100049, China \\ 3 School of Economics, Hebei University of Geosciences, Shijiazhuang 050031, China; quqs.16b@igsnrr.ac.cn \\ * Correspondence: lmwang@igsnrr.ac.cn (L.W.); zhongshuai@igsnrr.ac.cn (S.Z.)
}

check for updates

Citation: Wang, B.; Wang, L.; Zhong, S.; Xiang, N.; Qu, Q. Low-Carbon Transformation of Electric System against Power Shortage in China: Policy Optimization. Energies 2022, 15, 1574. https://doi.org/10.3390/ en15041574

Academic Editor: Ignacio Mauleón

Received: 20 January 2022

Accepted: 18 February 2022

Published: 21 February 2022

Publisher's Note: MDPI stays neutral with regard to jurisdictional claims in published maps and institutional affiliations.

Copyright: (C) 2022 by the authors. Licensee MDPI, Basel, Switzerland. This article is an open access article distributed under the terms and conditions of the Creative Commons Attribution (CC BY) license (https:// creativecommons.org/licenses/by/ $4.0 /)$.

\begin{abstract}
The low-carbon transition of the power system is essential for China to achieve peak carbon and carbon neutrality. However, China could suffer power shortages due to radical policies in some extreme cases. The gap between power demand and supply from March 2021 to November 2021 ranged between 5.2 billion $\mathrm{kW} \cdot \mathrm{h}$ and 24.6 billion $\mathrm{kW} \cdot \mathrm{h}$. The main reason for the power shortage was over-reliance on renewable energy and insufficient coal power supply for the power system. The low-carbon transformation path of the electric system needs to be explored with more flexibility for power security. This study applied a modified LEAP model and carried out a forecast analysis of thermal power generation and installed capacity in 2025 and 2030 under normal and extreme weather scenarios. The results suggested that: the installed capacity of thermal power will need to account for about $44.6-46.1 \%$ of power generation in 2025 and 37.4-39.3\% in 2030, with the assumption of power shortages caused by the instability and uncertainty of renewable power. In the future, China needs to pursue the development of diversified energy sources and enhance the power supply security capability while strengthening the development and utilization of renewable energy.
\end{abstract}

Keywords: power shortage; electric system; installed capacity; low-carbon transformation; policy optimization

\section{Introduction}

In September 2021, more than ten provinces in China suspended the operation of industries and restricted household electricity consumption, which seriously affected residents' daily lives and increased the sensitivity of the whole of society [1]. This phenomenon can be summarized as having resulted from imbalance between power supply and power demand due to some aggressive low-carbon policies.

Low-carbon development in addressing climate change is crucial, motivating reformation of the energy system all over the world [2]. At the 75th session of the UN General Assembly, Chinese President Xi stated that China will seize the opportunity to formulate an action plan to achieve peak carbon dioxide emissions before 2030 and to achieve carbon neutrality by 2060 [3]. To achieve this goal, energy transition from coal to non-fossil energy in all industries has been accelerated [4], especially in the power sector due to its significant contribution to carbon emissions $[3,5]$. In terms of the electricity sector, the needs are to improve energy efficiency and promote the development of renewable energy, such as solar power, wind power, hydropower, nuclear power, and others, which dominate the low-carbon transformation in many countries [6-8]. President Biden directed the electricity program to achieve $100 \%$ clean electricity by 2035 [9], with decarbonization policies in the US supporting zero-carbon generation, and reduction in carbon intensive generation [10]. Germany plans to generate $80 \%$ of its electricity from renewable sources by 2030 [2,11]. The European Union (EU) aims to fully develop solar power and wind power, and offshore 
wind power is expected to undergo a 25-fold increase [6]. Japan is paying increasing attention to development of nuclear power and hydrogen energy [12].

It is clear that renewable energy in the electricity sector will develop considerably $[7,13]$. By 2030, wind and solar power are expected to grow by $1.4-2.9 \%$ and $1.4-2.3 \%$, respectively, across the world [9]. However, a power generation system that installs more renewable energy can lack reliability and stability due to the uncertainty and constraints of solar and wind power $[14,15]$. This is a great challenge for a low-carbon transition in the electricity sector. Many countries need to use thermal power to provide flexibility [2]. In Australia, use of coal power has not been ended because Australia has abundant coal resources and the ratio of coal power to other sources is relatively high [6].

There is still a long way to go to optimize policies for a low-carbon transition of the power system in China. Three main characteristics need to be considered during the process of low-carbon transition in the electricity sector: Firstly, power demand will keep increasing with economic development and improvement in people's livelihoods $[16,17]$. Secondly, China has an endowment of coal resources, and thus coal still dominates as the main source of energy consumption [18], which has created further challenges for the energy transformation of China's electric system [5,19]. Thirdly, China's energy resources vary greatly from region to region, which produces a mismatch between energy distribution and energy demand, especially in the power system [14]. Fossil energy is mainly distributed in the north of China, and water resources are mainly distributed in the east of China [20]. Solar and wind resources also have an uneven distribution. Additionally, other factors also affect the low-carbon transition, such as China's relatively low electricity price compared with other countries [21,22].

Overall, based on China's power system characteristics, the low-carbon transition in China's electric system needs to avoid the imbalance between power supply and demand caused by some radical policies [23]. China's policies for controlling energy consumption intensity and total amount have been seen as key contributors to the power shortage. Measures involving power and coal controls placed on enterprises caused China's electric system to suffer an imbalance between power demand and supply [24]. Under huge policy pressure, the production of coal is strictly limited, and the utilization hours of thermal power are expected to be in a long-term downturn [25]. Limiting energy use, and reducing energy intensity, have seriously affected social and economic development in China.

Many studies have applied the LEAP model, for example, to predict electricity consumption and supply, types of costs, and GHG emissions over a 20-year period (2011-2030) in Iranian thermal power plants [26]. Pakistan's electricity demand and supply from 2015 to 2050 were forecast for four scenarios, considering resource potential, techno-economic parameters, and $\mathrm{CO}_{2}$ emissions [27]. The Ecuadorian power generation system was simulated using the LEAP model to analyze possible alternatives for electricity supply and demand, fuel consumption, and the future structure of the Ecuadorian power generation system [28]. Electricity demand in Indonesia in 2025 was forecast to be more than two-fold greater than in 2010 under both a 'business as usual' scenario and a government policy scenario [29].

As for China, Chen and others used the LEAP model to predict energy demand in Changsha, Hunan Province for various scenarios, and discussed the impact of GDP growth rate, industrial structure, and energy conservation targets on energy demand [30]. Guang built a LEAP model to predict China's electricity demand and electricity generation in 2030 under different scenarios [31]. Using the LEAP model, Ma and others set up four scenarios, analyzed the medium- and long-term emission reduction path planning of the electric sector, and comprehensively evaluated each emission reduction path from the perspective of emission reduction and emission reduction cost [32]. Huang used the LEAP model to consider three scenarios-a strong electrification scenario, a baseline scenario, and a weak electrification scenario-and, for each of these, considered China's electricity demand in 2020, 2030, 2040, and 2050 [33]. 
Existing studies concerning power shortage are still insufficient, especially regarding its severity with respect to the nature of installed capacity in the electric system, its driving factors and impacts, as well as policy optimization. This study applied the LEAP model, with some modifications, to address the following questions: (1) What is the gap between power demand and supply, and how is this gap reflected in the relationship between the growth of raw coal production growth and the growth of power generation? (2) Why did China have a power shortage at the beginning of the 14th Five-year Plan period? In other words, what factors seriously affect power supply capacity in China? (3) How can the power consumption of the whole society be guaranteed, considering extreme weather conditions, when the utilization of wind and solar power generation is extremely low? In particular, it is considered that the installed capacity and generation of thermal power are vital to the low-carbon transition process of the power system. This study aims to optimize policies related to the low-carbon transformation of the electric system to avoid power shortage, and proposes strategies for the development of installed power generation capacity considering both normal and extreme weather circumstances.

\section{Background of Power Shortage in China}

Since May 2021, the power shortage in China has led most provinces to control power consumption in industries and enterprises.

\subsection{The Balance between Power Demand and Supply in China in 2021}

After the proposal of a peak carbon emissions target, policies have been implemented more rigorously, affecting social and economic development. China's power demand and supply from March 2021 to November 2021 are shown in Figure 1. Thermal power still contributed most to power generation in China (70.11\%), while hydropower, wind power, nuclear power, and solar power accounted for $16.18 \%, 6.35 \%, 5.13 \%$, and $2.24 \%$, respectively.

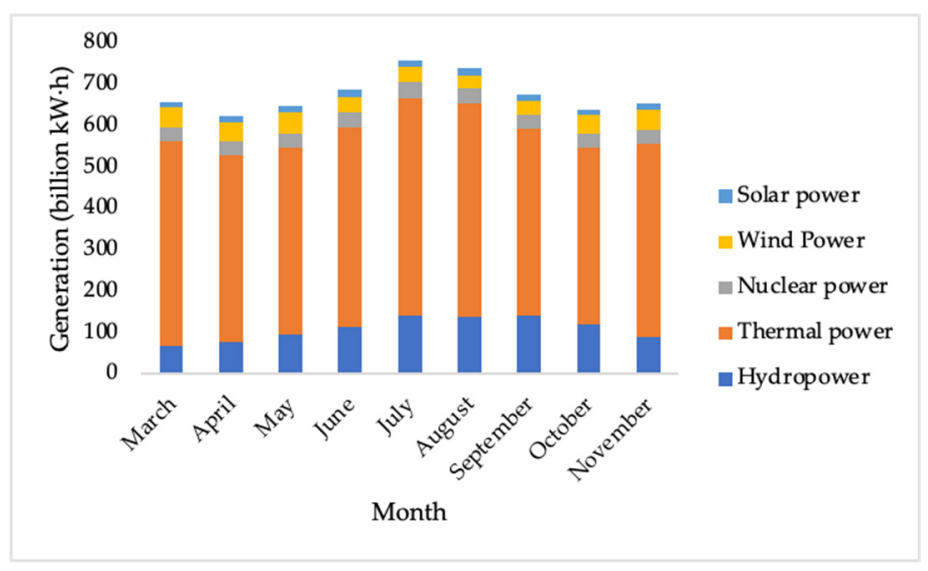

Figure 1. Generation of various energy sources.

Comparing China's power demand and supply from March to November 2021, there was a big gap between power demand and supply because power supply had not kept up with power demand. Table 1 shows that this gap ranged from 5.2 billion $\mathrm{kW} \cdot \mathrm{h}$ to 24.6 billion $\mathrm{kW} \cdot \mathrm{h}$, with the maximum gap occurring in May 2021. This imbalance was not alleviated or resolved in the following months and then caused a severe power shortage. 
Table 1. Power demand-supply gaps from March to November 2021.

\begin{tabular}{cccc}
\hline Month & $\begin{array}{c}\text { Power Demand } \\
\text { (Billion } \mathbf{k W} \cdot \mathbf{h})\end{array}$ & $\begin{array}{c}\text { Power Supply } \\
\text { (Billion } \mathbf{k W} \cdot \mathbf{h})\end{array}$ & $\begin{array}{c}\text { Power Demand-Power } \\
\text { Supply (Billion } \mathbf{k W} \cdot \mathbf{h})\end{array}$ \\
\hline March & 663.1 & 657.9 & 5.2 \\
April & 636.1 & 623.0 & 13.1 \\
May & 672.4 & 647.8 & 24.6 \\
June & 703.3 & 686.1 & 17.2 \\
July & 775.8 & 758.6 & 17.2 \\
August & 760.7 & 738.4 & 22.3 \\
September & 694.7 & 675.1 & 19.6 \\
October & 660.3 & 639.4 & 20.9 \\
November & 671.8 & 654.0 & 17.8 \\
\hline
\end{tabular}

In the first three quarters of 2021, there was a significant gap between the growth rate of raw coal production and that of power generation. From January to September, raw coal production increased by $3.7 \%$ year-on-year, an average increase of $1.8 \%$ in two years, while power generation increased by $10.7 \%$ year-on-year, with an average increase of $5.7 \%$ in two years. The monthly growth trend of large-scale industrial coal production was basically of negative growth or of a slight increase. In contrast, the monthly growth trend of large-scale industrial thermal power generation continued in high growth. The comparative relationship among generation, GDP and coal production is shown in Table 2 and Figure 2.

Table 2. The growth rate of power generation, GDP, coal production and imported coal amount.

\begin{tabular}{|c|c|c|c|c|}
\hline Period & $\begin{array}{c}\text { Year-on-Year } \\
\text { Growth Rate of } \\
\text { Power Generation }\end{array}$ & $\begin{array}{c}\text { GDP Year-on-Year } \\
\text { Growth Rate }\end{array}$ & $\begin{array}{c}\text { Year-on-Year } \\
\text { Growth Rate of } \\
\text { Coal Production }\end{array}$ & $\begin{array}{c}\text { Year-on-Year } \\
\text { Growth Rate of } \\
\text { Imported Coal }\end{array}$ \\
\hline $\begin{array}{l}\text { The first three } \\
\text { quarters of } 2018\end{array}$ & 7.4 & 6.7 & 5.1 & 11.8 \\
\hline $\begin{array}{l}\text { The first three } \\
\text { quarters of } 2019\end{array}$ & 3.0 & 6.2 & 4.5 & 9.5 \\
\hline $\begin{array}{l}\text { The first three } \\
\text { quarters of } 2020\end{array}$ & 0.9 & 0.7 & -0.1 & -4.4 \\
\hline $\begin{array}{l}\text { The first three } \\
\text { quarters of } 2021\end{array}$ & 10.7 & 9.8 & 3.7 & -3.6 \\
\hline
\end{tabular}

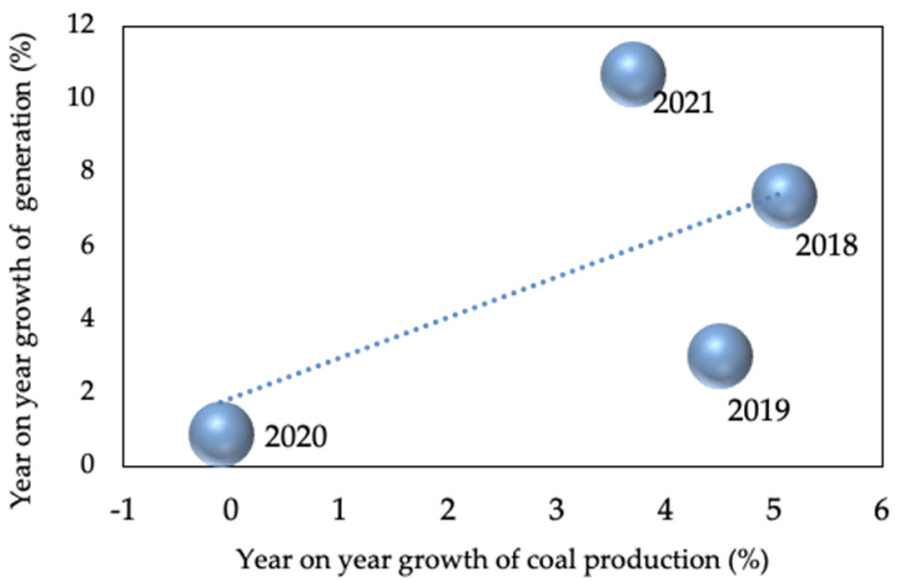

Figure 2. Comparative relationship between the growth of power generation and coal production.

According to year-on-year growth rate data of various energy sources, in the first three quarters of 2018 to 2021, the power supply was adequate under the circumstances of a yearon-year growth rate of power generation, coal production, and imported coal occurring at the same time. In the first three quarters of 2021, China's power generation grew by 
$10.7 \%$ year-on-year, and coal production grew by 3.7\% year-on-year, while coal imports increased by $-3.6 \%$. In the circumstance of a limited proportion of hydropower and a small proportion of wind and solar power, the risk of power shortage was inevitable [24].

In the first three quarters of 2021, the year-on-year growth rate of wind power and thermal power was the highest, while that of hydropower was relatively small, indicating that its technical level and other features cannot substantially replace thermal power (Figure 3). For enterprises, using renewable energy with less than $20 \%$ of installed capacity and less than $10 \%$ of power generation to contribute to more than $70 \%$ of industrial profit is the most significant barrier that causes power shortage risks.

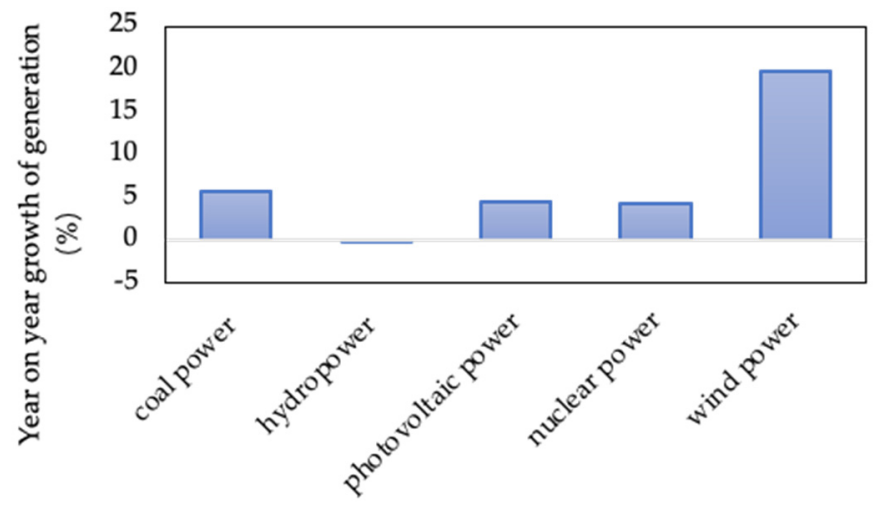

Power types

Figure 3. The growth rate of each power generation type in the first three quarters of 2021.

\subsection{Driving Factors}

From September 2021, many provinces in China issued a warning notice on orderly power consumption. Shandong province, for instance, announced that the power supply capacity of Shandong power grid would decrease sharply due to the supply-demand imbalance of coal and the extreme high temperature, and then a large power gap occurred [34]. For northeast China, as a result of coal shortages, the large shutdown capacity of thermal power, the small generation by renewable energy, and the growth of power load, the power supply in the northeast power grid continues to be tight [35]. On 22 September, the Office of the Leading Group for Energy Supply in Anhui province also issued an emergency notice on the orderly use of electricity due to the coal shortage for thermal power and the abnormal operation of generator sets [36]. In short, policies might exacerbate the imbalance of power supply and demand because of the government's strong climate agenda [24].

Firstly, dual control policy, concentrating on the control of energy intensity and the total amount of energy consumption, has strictly restricted coal development. Since 2016, driven by the coal overcapacity reduction policy, three provinces in northeast China have withdrawn a large amount of coalmine capacity. On 1 March 2021, the Amendment to the Criminal Law of the People's Republic of China (XI) was officially implemented, criminalizing the act of production beyond approved capacity. Therefore, the overproduction of coal has been greatly reduced. It is notable that China's thermal coal stocks are nearly 90 million tons lower than last year. In addition, the available days for storing coal in key power plants nationwide dropped to 10.3 days, far below the red line requirement of 20 days in the off-season [37].

Secondly, climate target policy constraining thermal power development increases the risks of power shortage. In recent years, with the goal of carbon neutrality, China has continued to reduce carbon emissions from thermal power, as well as thermal power installed capacity [38]. Thermal power entered a low-speed growth stage [39]. However, under conditions of high growth in power demand, clean and low-carbon energy is insufficient to guarantee supply capacity. During the Thirteenth Five-Year Plan period, electricity demand grew relatively rapidly (2017 and 2018), which pushed thermal power supply to grow at 
a high speed to achieve balance. If thermal power is excessively suppressed or ignored, power shortages may occur [38].

Thirdly, there is too much responsibility for renewable energy in the power system. On 22 September 2021, the CPC Central Committee and the State Council issued their "Comments on Fully and Accurately Implementing the New Development Philosophy to Achieve Peak Carbon and Carbon Neutrality". The comments pointed out that the proportion of non-fossil energy consumption in China will reach over $80 \%$ by 2060 [40]. However, the fact is that renewable energy generation technology does not perform well. Due to the randomness, volatility, and intermittent nature of renewable energy power, the current power system, with a high proportion of renewable energy, cannot meet the fixed demand of the economy for electricity. During peak load periods, generation from renewable energy is low, which leads to the difficulty of peak load regulation of the electric system [41]. Solar power, for example, cannot contribute to electricity consumption at night. As the proportion of renewable energy continues to grow, it is difficult to ensure the stability of the electric system. Traditional relay protection is difficult to adapt to the nonlinear changes following renewable energy access to the electric system. Renewable energy power generation should be connected to an AC power system through the converter. When a large number of distribution networks are connected to distributed power generation, interlocking faults become the new normal of faults in the AC/DC hybrid power grid [42]. Additionally, the power operation system has increasingly suffered uncertainty problems, and the voltage, frequency, and regulation capabilities are facing severe tests. For example, the electric system can encounter problems, such as wind curtailment, solar abandonment, and insufficient power supply [43-45].

\section{Methods and Data}

\subsection{LEAP Model with Modification}

There are many models for energy system planning, and those frequently applied mainly include MARKAL/TIMES, EnergyPLAN, DER-CAM, HOMER, and the LEAP model. The MARKAL/TIMES model is applicable to the long-term impact analysis of macro energy economic systems. The EnergyPLAN model focuses on the design and evaluation of sustainable energy systems for renewable energy applications. The DERCAM model is an ideal planning tool for grid connected distributed energy microgrids with peak capacity of 250-2000 $\mathrm{kW}$. The HOMER model is applicable to the design, optimization and feasibility evaluation of low power off grid/grid connected microgrids [46]. The advantage of the LEAP model is the analysis of medium and long-term energy supply and demand balance, which is of great relevance to this research. In this study, we applied the LEAP model, with modification, in constructing the least cost model of electric system capacity expansion. We explored the optimum installed capacity of thermal power, wind power, solar power, hydropower, and nuclear power, with a view to optimizing policies related to the low-carbon transformation of the electric system to avoid power shortage.

LEAP is an energy demand forecasting model based on sector analysis, which has been widely applied to national, regional, and industrial sector energy strategy [47], for energy policy analysis and climate change mitigation assessment [48]. This model was developed by the Stockholm Environment Institute and Boston University. The dataset in the LEAP model includes four modules. The key assumptions module mainly sets the status of economic and social development and the key factors affecting the energy environment, including GDP, population, industrial structure, family size and others. The demand module describes the energy demand sectors, including residents, industry, commerce, transportation, agriculture and others. Power demand scenario analysis is mainly reflected in the LEAP model's energy demand module, which is composed of various energy terminal demand sectors. The transformation module refers to the transformation process of primary energy to secondary energy, including power generation and power transmission and distribution. The power generation module includes coal power, natural gas power, wind power, solar, hydropower, and nuclear power. Resources mainly include a series of energies 
involved in the model, including primary and secondary energies. The simulation analysis of the energy system in this model is based on the medium and long term, with one year as the unit of calculation. The principle of the modified LEAP model is shown in Figure 4.

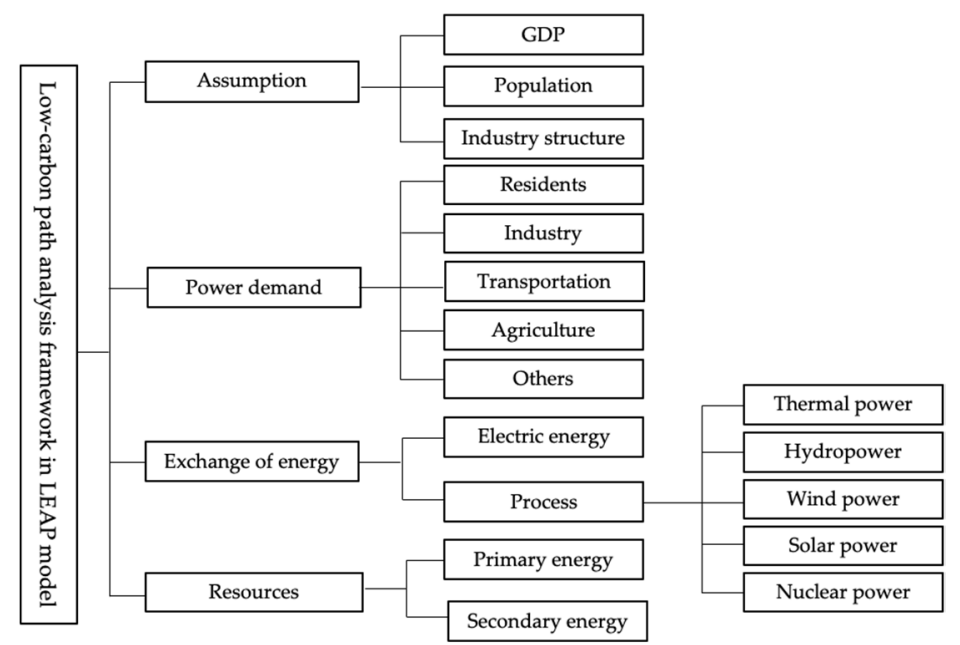

Figure 4. The principle of the LEAP model with modification.

The LEAP model also has limitations. It does not consider transmission network capacity constraints and power plant spatial analysis [49]. The quantification of departmental demand, market development potential and future development goals in the LEAP model depend on the subjective judgment of researchers [46]. These limitations have little impact on this study. The equation and some constraints in this study, are as follows,

$$
\operatorname{MinC}=\sum_{\substack{\forall m \in \text { tech } \\
\forall n \in \text { year }}}\left(\begin{array}{c}
I A_{m, n} \times I C_{m, n}+T A_{m, n} \times F M_{m, n}+T P_{m, n} \times V M_{m, n} \\
+T P_{m, n} \times F C_{m, n}+C E_{m, n} \times C D_{n}
\end{array}\right)
$$

where $C$ is the total cost of generating units in the life range; $I A_{m, n}, I C_{m, n}, T A_{m, n}, F M_{m, n}$, $T P_{m, n}, V M_{m, n}, F C_{m, n}, C E_{m, n}$ are the new installed capacity, the investment cost, the total installed capacity, the fixed operating and maintenance costs, the total generating capacity, the variable operating and maintenance costs, the fuel costs, and the total carbon dioxide emissions of type $m$ units in year $n$, respectively. $C D_{n}$ represents the carbon dioxide emission reduction costs in $\mathrm{n}$ years.

The total power generation minus the power loss of transmission lines should meet the total power demand, as shown in Formula (2).

$$
\left(1-T L_{n}\right) \times \sum_{m}^{p}\left(T A_{m, n} \times C C_{m, n} \times M H_{m, n}\right) \geq T D_{n}
$$

where $T L_{n}$ is the rate of transmission electric line loss; $C C_{m, n}$ refers to the capacity reliability of $m$ types of units, the share of power plant in rated installed capacity. The capacity reliability of thermal power plants and hydropower plants is $100 \%$, while the capacity reliability of renewable energy is low; $M H_{m, n}$ refers to the maximum utilization rate of type $m$ units and the maximum utilization hours of units in a year; $T D_{n}$ is the total electricity demand in year $n ; p$ represents the number of each type of power generation.

The ratio of actual generating capacity to theoretical generating capacity of each type of unit is less than or equal to the capacity factor, as shown in Formula (3).

$$
C C_{m, n} \times M H_{m, n} \leq U L_{m, n}
$$

$U L_{m, n}$ refers to the upper operating rate of type $m$ units (generating capacity factor). 
The total installed capacity of the system reserve rate should be greater than or equal to the annual maximum load demand of the power system to ensure that the power system has sufficient capacity to ensure its safe, stable and reliable operation, as shown in Formula (4).

$$
\sum_{t}^{n} T A_{m, n} \times\left(1+S R_{n}\right) \geq M L_{n}
$$

where $S R_{n}$ represents the system reserve rate and $M L_{n}$ represents the maximum annual load requirement of the system.

The constraint of installed capacity includes two conditions, one is the constraint of upper and lower limits of installed capacity of new units; the other is the upper and lower limits of the total installed capacity of the system.

$$
\begin{aligned}
I A_{m, n} & \leq I A_{m, n, \max } \\
I A_{m, n} & \geq I A_{m, n, \min } \\
\sum_{m}^{p} T A_{m, n} & \leq \sum_{m}^{p} T A_{m, n, \text { max }} \\
\sum_{m}^{p} T A_{m, n} & \geq \sum_{m}^{p} T A_{m, n, \text { min }}
\end{aligned}
$$

where $I A_{m, n, \max }, I A_{m, n, m i n}$, respectively, represent the maximum and minimum newly installed capacity of type $m$ units in year $n ; T A_{m, n, \max }, T A_{m, n, m i n}$, respectively, represent the upper and lower limits of the annual total installed capacity.

The installed capacity of renewable power and the proportion of its electricity generation in the total installed capacity and the total generation need to reach a certain proportion target, and then the renewable energy target constraint should be added.

$$
\begin{aligned}
& \sum_{m}^{p} T A_{m, n} \geq \sum_{m}^{p} T A_{m, n} \times C R_{n} \\
& \sum_{m}^{p} R E_{m, n} \geq \sum_{m}^{p} R E_{m, n} \times G R_{n}
\end{aligned}
$$

where $\sum_{m}^{p} T A_{m, n}, C R_{n}$, respectively, represent the installed capacity of renewable energy in the power system in year $n$ and the proportion of the total installed capacity; $\sum_{m}^{p} R E_{m, n}$, $G R_{n}$, respectively, represent the proportion of renewable energy generation in the power system in year $n$.

Total carbon dioxide emissions during the study period must not exceed their emission limits, as shown in Formula (11).

$$
\sum_{m}^{p} C E_{m, n} \leq \sum_{m}^{p} C O_{2 n, \max }
$$

$\sum_{m}^{p} C E_{m, n} \sum_{m}^{p} C O_{2 n, \max }$ represents the total GHG emission and maximum emission of the power industry during the study period, respectively.

Considering the two main factors causing the power shortage in China, the climate vulnerability of renewable power and the decreased proportion of thermal power in the electric system, low-carbon transformation policies for the electric system should be optimized to be suitable for various situations. The low-carbon development of the power system must pass the test of small probability events, such as extreme weather. In this study, two future scenarios are simulated using the modified LEAP model. 


\subsection{Key Assumptions and Demand Module Data Setting}

1. GDP growth rate

According to the research-based prediction of China's future long-term economic growth trend (Table 3), China's potential GDP will grow at an average annual rate of 5.5\% in 2022 [50]. Additionally, China's economy will grow by about 5.3\% in 2022 [51]. The added value of primary, secondary and tertiary industries can be calculated from their proportion in the national economy.

Table 3. The prediction of GDP growth rate in China.

\begin{tabular}{ccccc}
\hline Year & $\begin{array}{c}\text { GDP } \\
\text { Growth } \\
\text { (\%) }\end{array}$ & $\begin{array}{c}\text { Proportion of Added } \\
\text { Value of Primary } \\
\text { Industry in GDP (\%) }\end{array}$ & $\begin{array}{c}\text { Proportion of Added } \\
\text { Value of Secondary } \\
\text { Industry in GDP (\%) }\end{array}$ & $\begin{array}{c}\text { Proportion of Added } \\
\text { Value of Tertiary } \\
\text { Industry in GDP (\%) }\end{array}$ \\
\hline 2020 & 5.1 & 7.7 & 37.8 & 54.5 \\
2025 & 5.5 & 7.3 & 34.5 & 58.2 \\
2030 & 5.0 & 6.0 & 32.1 & 61.9 \\
\hline
\end{tabular}

\section{Population}

According to the "Green paper on population and labor: No.19 report on China's population and labor issues" [52] (Table 4), the fertility rate from 2025 to 2030 will be 1.69. China's population will reach a peak of 1.442 billion in 2029 and enter negative growth from 2030. The "Green paper on population and labor: No.22 report on China's population and labor issues" gives a prediction of the urbanization rate [53].

Table 4. The prediction of population in China.

\begin{tabular}{ccccc}
\hline Year & $\begin{array}{c}\text { Population } \\
\text { (Billion) }\end{array}$ & $\begin{array}{c}\text { Urban } \\
\text { Population } \\
\text { (Billion) }\end{array}$ & $\begin{array}{c}\text { Rural } \\
\text { Population } \\
\text { (Billion) }\end{array}$ & $\begin{array}{c}\text { Urbanization } \\
\text { Rate (\%) }\end{array}$ \\
\hline 2020 & 1.412 & 0.902 & 0.510 & 63.89 \\
2025 & 1.435 & 1.004 & 0.431 & 70.00 \\
2030 & 1.442 & 1.081 & 0.361 & 75.00 \\
\hline
\end{tabular}

\subsection{Number of Utilization Hours of Power Generation Equipment by Type}

China's utilization hours of wind power and solar power could be $2378 \mathrm{~h}$ and $1658 \mathrm{~h}$ in 2025. In 2030, the utilization hours of wind power could be $2616 \mathrm{~h}$, while the utilization hours of solar power could be $1930 \mathrm{~h}$ [54].

\subsection{Scenario Settings}

\section{Normal scenario}

Assumes that all power generation is in regular operation, including thermal power, nuclear power, and renewable power. Generation from renewable energy power would not be affected by the weather.

\section{Extreme weather scenario}

This scenario is based on China's power supply situation on 7 January 2021. There was zero generation from solar power and the utilization of wind power was about $10 \%$. Meanwhile, more than 200 million $\mathrm{kW}$ of installed hydropower at the peak did not work because of the dry season. Thermal power with more than $90 \%$ capacity and nuclear power with $100 \%$ capacity supported the peak load on that day. Table 5 illustrates the proportion of available installed capacity in the extreme weather scenario. 
Table 5. Generation of various energy types on 7 January 2021.

\begin{tabular}{ccccc}
\hline $\begin{array}{c}\text { Type of } \\
\text { Generation }\end{array}$ & $\begin{array}{c}\text { Installed } \\
\text { Capacity in 2020 } \\
\text { (MW) }\end{array}$ & $\begin{array}{c}\text { Unavailable } \\
\text { Installed } \\
\text { Capacity (MW) }\end{array}$ & $\begin{array}{c}\text { Available } \\
\text { Installed } \\
\text { Capacity (MW) }\end{array}$ & $\begin{array}{c}\text { The Proportion } \\
\text { of Available } \\
\text { Installed } \\
\text { Capacity (\%) }\end{array}$ \\
\hline Total & $2,200,580$ & 828,090 & $1,372,090$ & 62.5 \\
Thermal power & $1,245,170$ & 121,280 & $1,123,890$ & 90.3 \\
Hydropower & 370,160 & 200,000 & 170,160 & 46.0 \\
Wind power & 281,530 & 253,380 & 28,150 & 10.0 \\
Solar power & 253,430 & 253,430 & 0 & 0.0 \\
Nuclear power & 49,890 & 0 & 49,890 & 100.0 \\
\hline
\end{tabular}

It is predicted that $10 \%$ of the year is characterized as extreme weather, where the proportion of available installed capacity refers to the situation on 7 January 2021. It is assumed that extreme weather events will occur every year from 2025 to 2030. Although this assumed prediction seems overly pessimistic, the increasing frequency of extreme weather events leads us to believe that this setting is relevant.

In recent years, large-scale blackouts caused by extreme weather have occurred all over the world. On 28 September 2016, a strong typhoon hit South Australia with storms, lightning and hail. A series of faults, such as the large-scale disconnection of wind turbines, eventually evolved into a 50-h nationwide blackout [55]. Since 14 February 2021, affected by the extremely cold weather, the power load in Texas has increased sharply, wind turbines have frozen, and a large number of ice blocks have formed in the natural gas transmission pipeline, resulting in a serious imbalance between power supply and demand. A large-scale power outage occurred in Texas for several days [56].

According to research from the World Meteorological Organization, there would be more than ten days every year without light or wind [57]; that is to say, solar and wind power will fail to generate electricity during this period. Although extreme weather is a low probability event, once this phenomenon occurs, it would inevitably result in the problem of an imbalance between power supply and demand. As a result, setting the extreme weather scenario to primarily focus on meeting electricity consumption needs for the whole of society is essential.

\section{Results}

\subsection{Installed Capacity of Thermal Power under Normal Conditions}

In 2025 , the installed capacity thermal power is predicted to be 1.28 billion $\mathrm{kW}$, accounting for $44.6 \%$ of the total power installed capacity. In 2030, the installed capacity of thermal power is predicted to be 1.31 billion $\mathrm{kW}$, accounting for $37.4 \%$ of total power installed capacity. Figure 5 illustrates the installed capacity of various energy sources in 2025 and 2030 under normal conditions.

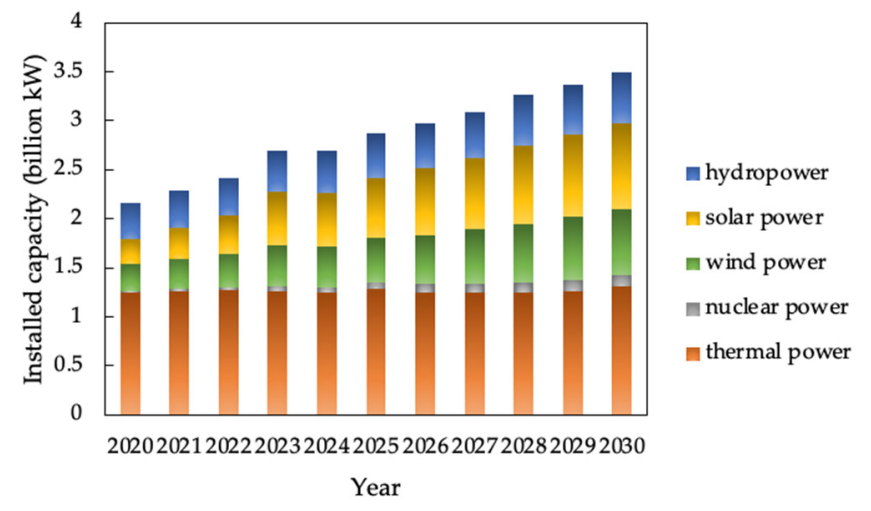

Figure 5. Installed capacity of various energy sources in 2025 and 2030 under normal conditions. 
Many researchers have forecast China's power demand in the future, assuming that all the power generators are operating properly. The thermal power generation in 2025 and 2030 under the usual scenario predicted in this study is basically consistent with others' predictions [58,59]. Moreover, the expected proportion of thermal power installed capacity in 2030 agrees with the research of Shu YB [59]. The installed capacity of thermal power in 2030 (37.4\%) could be much lower than that in 2020 (56.6\%). However, the predicted proportion of thermal power installed capacity in 2030 in Zhang's research (62.1\%) in a normal scenario and $46.1 \%$ in a low-carbon scenario is higher than in our study [60]. Different predictions of power demand in 2030 would lead to this result. Findings in our study are more consistent with the future development situation. In conclusion, the decline of both the generation and installed capacity of thermal power is in line with China's energy structure transformation target under the normal scenario.

\subsection{Installed Capacity of Thermal Power under the Condition of Extreme Weather}

The installed capacity of thermal power would be 1.36 billion $\mathrm{kW}$ in 2025 and 1.42 billion $\mathrm{kW}$ in 2030 , which accounts for $46.1 \%$ and $39.3 \%$ of the total power installed capacity. Figure 6 illustrates the installed capacity of various energy sources in 2025 and 2030 under the extreme weather condition.

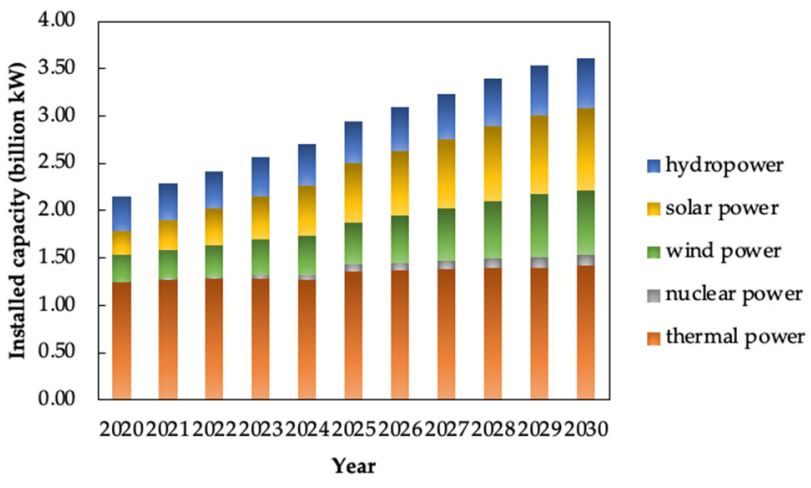

Figure 6. Installed capacity of various energy sources under the extreme weather condition.

In the extreme weather scenario, the installed capacity of thermal power is larger than those in other studies. Previous findings were mostly based on policy scenarios, low-carbon scenarios, or deep low-carbon scenarios. They assumed that renewable power would play an increasingly important role in China's electric system and that all types of power are in normal operation. Most of these studies analyzed thermal power generation with carbon emission reduction as the main goal, while our study emphasized the balance between power demand and supply. In the extreme weather scenario, our study assumed that wind power and solar power would not generate as regularly all the year because of the uncertainty and volatility of renewable energy. Thermal power, therefore, should contribute more generation to meet the power demand. As a result, the installed capacity would be higher than others' predictions.

\subsection{Policy Optimization of Low-Carbon Transition of Power System Based on the Power Demand Assurance}

In conclusion, the installed capacity proportion of wind power and solar power would increase from $25 \%$ in 2020 to $40 \%$ in 2030 . Thermal power, accounting for about $44.6-46.1 \%$ in 2025 and $37.4-39.3 \%$ in 2030, would still play a fundamental role in China's power system. Table 6 and Figure 7 illustrate the installed capacity of various power generation types. 
Table 6. Installed capacity of various power generation types in extreme weather conditions (billion $\mathrm{kW})$.

\begin{tabular}{ccccc}
\hline \multirow{2}{*}{$\begin{array}{c}\text { Type of } \\
\text { Generation }\end{array}$} & $\begin{array}{c}\text { Installed } \\
\text { Capacity } \\
\text { (Billion kW) }\end{array}$ & Proportion (\%) & $\begin{array}{c}\text { Installed } \\
\text { Capacity } \\
\text { (Billion kW) }\end{array}$ & Proportion (\%) \\
\hline Thermal power & 1.36 & 46.1 & 1.42 & 39.3 \\
Hydropower & 0.50 & 16.9 & 0.53 & 14.7 \\
Wind power & 0.43 & 14.6 & 0.68 & 18.8 \\
Solar power & 0.58 & 19.7 & 0.87 & 24.1 \\
Nuclear power & 0.08 & 2.7 & 0.11 & 3.0 \\
\hline
\end{tabular}

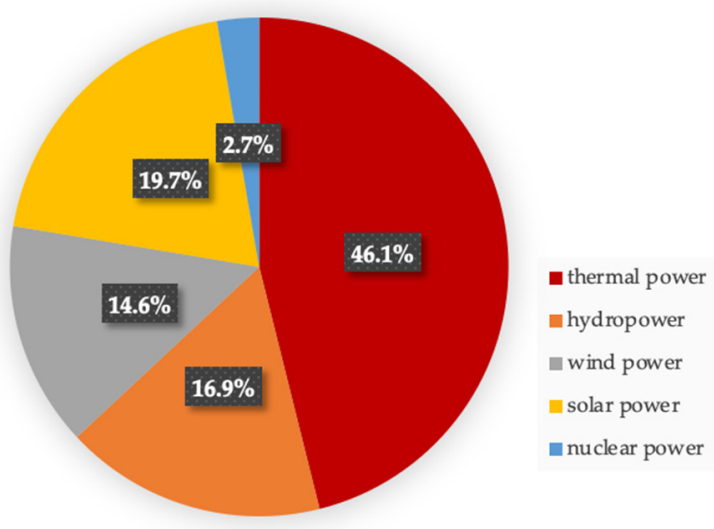

(a)

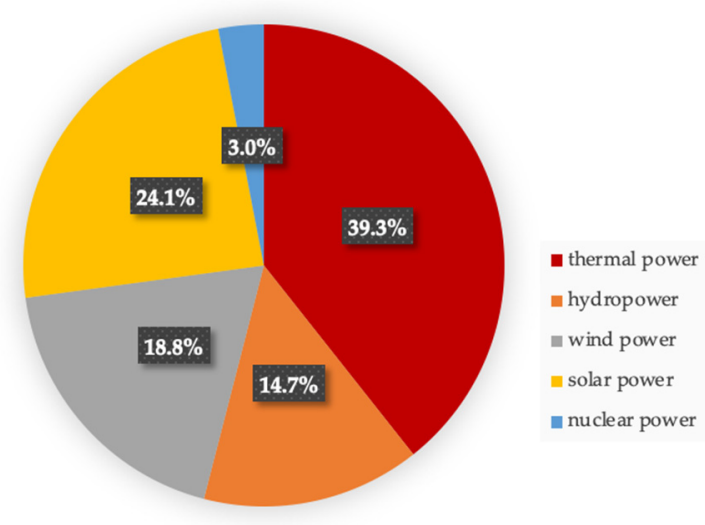

(b)

Figure 7. The proportion of installed capacity of various energy sources under the extreme weather condition. (a) The projected value for 2025; (b) The projected value for 2030.

From the point of view of renewable power supply in China and other countries, such as Germany and US [61], generation from renewable power is insufficient during the loading peak period, especially in extreme conditions. The power shortage in China in 2021 has highlighted some problems, such as over-reliance on renewable energy and insufficient coal power supply for the power system. It reflects the fact that there are structural problems in China's power supply, and that the estimation of renewable energy generation output might be too optimistic. Frequent extreme weather is the biggest uncertainty factor leading to low generation from renewable energy power in the future [62]. Therefore, the flexibility of power regulation, the accuracy of the renewable power generation prediction, and the technology of power storage need to be further improved [63-65].

In the process of the low-carbon transformation of electric energy, it is necessary to ensure that thermal power plays the role of ensuring the electricity demand for the whole of society [66]. By 2025, the installed capacity of thermal power would account for $44.6 \%$. By 2030, the installed capacity of thermal power would account for $37.4 \%$. In summary, China's electric system needs to avoid the radical transition of the energy system, and systematically promote the diversified development of power sources.

\section{Discussion}

Under the "dual control policy" and the "climate target", the annual installed capacity of wind power and solar power would be increased to alleviate power shortage. The annual newly installed capacity of wind power would be not less than 40 million KW, and that of solar power would be not less than 60 million KW. Overall, the annual newly installed capacity of wind and solar power would be between 80-120 million KW. Consequently, due to the unstable power supply of the power system dominated by renewable energy power, 
especially in extreme weather conditions, a certain scale of thermal power generation needs to be maintained. Coal fired units provide flexible dispatching operation modes, such as "peak regulation", "frequency regulation", etc., to provide technical support for the consumption of renewable energy power generation. The development of thermal power would follow the route of "increasing installed capacity and reducing generation", that is, the generation of thermal power would be controlled, but the installed capacity still needs to increase. It is estimated that the installed capacity of thermal power in 2030 would be 1.31 billion KW under normal conditions and 1.42 billion KW under extreme weather conditions.

The low carbon transformation also needs to consider the long-term costs. According to the "China provincial renewable power, competitiveness report 2019" released by the Wood Mackenzie organization, the average of LCOE (levelized cost of energy) of wind and solar power was already lower than the gas cost in China in 2019 [67]. As the generation cost of renewable energy falls, projects with solar power generation costs reaching the level of coal power generation costs have begun to appear in China since 2019 [68]. In June 2021, the National Development and Reform Commission in China issued a notice related to the price policy of renewable energy [69], requiring that the price of renewable energy projects in 2021 shall be implemented according to the local benchmark price of coal power generation. It is estimated that, by 2025, the cost of newly installed solar power generation is expected to be less than 0.3 yuan/ $\mathrm{kWh}$, and, by 2035, the cost of newly added solar power generation would be reduced to about 0.2 yuan $/ \mathrm{kWh}$. The cost advantage of solar power generation will become more and more apparent in the future [70].

However, due to the randomness, volatility, and intermittent nature of renewable energy power, a power system with a high proportion of renewable energy generation needs other power sources to maintain the stable and safe operation of the power system [71]. Therefore, a full cost evaluation of renewable energy utilization from the perspective of the safe and reliable operation of the entire power system is urgently needed. In the future, with increase in both the installed capacity and generation from renewable energy power, the utilization costs of renewable energy, including flexible power investment, system regulation and operation cost, large power grid expansion and reinforcement investment, and connection and distribution network investment, would also increase [72]. The higher the proportion of renewable energy, the higher the consumption cost. In addition, the consumption cost of renewable energy is still difficult to be reflected in the current mechanism design, so it is likely to push up the long-term costs of the electric system.

For instance, to meet the efficient and rapid regulation needs brought about by the continuous increase in renewable energy installed capacity, on the one hand, the scale of power side flexibility transformation is required to further increase, thus increasing the cost of power side transformation; on the other hand, a large number of pumping and storage power stations, energy storage and other rapid regulation resources need to be configured, increasing the construction investment on the energy storage side [73]. At present, the proportion of flexible power supply in China is less than 6\%. In northern China, the installed capacity of wind power and solar power is $72 \%$ and $61 \%$ respectively. However, power supply with flexible regulation is less than 3\% [74]. The flexibility transformation of China's conventional thermal power needs to be continuously promoted to maintain the reliability and stability of the electric system. The operational costs of the entire electric system would continue to rise, which may increase the power supply cost for the whole of society.

Furthermore, extreme weather increases the difficulty of power supply guarantee, especially in an electric system with a high proportion of renewable energy, which could increase power supply costs [75]. The installed capacity of thermal power would increase to meet the power demand, increasing the costs and causing a negative impact on the environment, while the relevant policy effects may be uncertain and diverse. Overall, in the process of the low carbon transformation of the electric system, we should not only 
consider the power generation cost of renewable energy, but also consider other costs, such as flexible power supply investment, system regulation and operation cost, etc.

It is often noted that policies should not only emphasize the role of thermal power in power security but also pay attention to how to overcome the shortcomings of renewable energy power. The following suggestions should be thoroughly considered.

First, the prediction of renewable energy generation could be more accurate. The greater the uncertainty of renewable energy output, the greater the need for reserve capacity and flexible resources [60]. Further improvement in the accuracy of forecasts can reduce the need for coal power regulation capacity.

Second, the instantaneous balance between power supply and demand could be more controllable. Especially in the event of extreme weather change, the maximum speed of frequency change of wind turbines and solar power stations needs to be well controlled to avoid sudden change of the output of the same amplitude caused by the instantaneous change of wind speed and light $[76,77]$.

Third, voltage control devices could be deployed on the renewable energy power supply side and grid side [78]. Sufficient resources are required to provide voltage control, even when the proportion of renewable energy is very high. Moreover, based on the transformation of low voltage traverse, renewable energy units could avoid off-grid, and even interlocking, faults by being equipped with high voltage traverse capability.

Fourth, constructing a new balance system to control power load demand, based on the capacity of renewable energy generation, is needed. To minimize the overall operating cost of the system, orderly guidance of load-side response, flexible transformation of coal power, pumped storage and electrochemical energy storage technology could participate in power grid regulation $[61,62]$. Additionally, in view of the conflict between power supply and heavy load periods in winter, energy storage equipment with high energy density and low storage loss should be configured.

\section{Conclusions and Policy Recommendation}

In this study, we focused on the problem of power shortage in China in 2021. First, power demand and supply from March 2021 to November 2021 were analyzed and the relationship between the growth rate of raw coal production and that of power generation was also analyzed to quantify the gap of power shortage. Second, three aspects of the driving factors for power shortage were considered. Third, the modified LEAP model was used to analyze the optimum installed capacity and generation of thermal power in 2025 and 2030 considering the regular situation and the extreme weather situation. Finally, some policy suggestions for the low-carbon transformation in China's electric system were proposed. The main findings of this study are as follows:

1. Controlling the total energy consumption and energy intensity led to power shortage in China in 2021. The gap between power demand and supply was from 5.2 billion $\mathrm{kW} \cdot \mathrm{h}-24.6$ billion $\mathrm{kW} \cdot \mathrm{h}$. In the first three quarters of 2021, China's power generation grew by $10.7 \%$ year-on-year and coal production grew by $3.7 \%$ year-onyear, while coal imports grew by $-3.6 \%$. The growth rate of imported coal, coal generation and power generation show a big difference.

2. Generation and installed capacity of thermal power in 2025 and 2030 were predicted in two scenarios. Under normal circumstance, the installed capacity of thermal power would be 1.28 billion $\mathrm{kW}$ in 2025 and 1.31 billion $\mathrm{kW}$ in 2030. Under the extreme weather circumstance, where the utilization of wind and solar power generation is extremely low, the installed capacity of thermal power would be 1.36 billion $\mathrm{kW}$ in 2025 and 1.42 billion $\mathrm{kW}$ in 2030.

3. Coal power supply must be guaranteed to ensure energy security. It is necessary to balance coal production, supply, stock, and consumption. Since wind power, solar power, and other renewable energy power are unstable and volatile, when the proportion of renewable energy increases to a high ratio in the electric system, the balance between power demand and supply could be broken. Policies should pay 
more concern for thermal power to avoid power shortage. Under the constraints of the carbon neutrality target, the development of thermal power needs to involve increase in the installed capacity while decreasing generation. Although the installed capacity of thermal power would keep increasing, the generating capacity could be controlled.

4. Energy consumption should be further reduced with progress in technology, and energy efficiency should be improved. The application of carbon dioxide capture, utilization and storage (CCUS) technology is currently at an exploratory stage. Energy consumption reduction requires national policy support, such as carbon pricing mechanisms or other forms of subsidy.

5. China needs to pursue the development of diversified energy sources and enhanced power supply security capability while strengthening the development and utilization of renewable energy. For renewable energy, the accommodation and storage capacity need to be enhanced. China should follow a more stable pathway with a gradually increasing proportion of renewable energy, and promotion of the large-scale, high proportion, market-based and high-quality development of renewable energy.

6. Continuous improvement in the energy emergency management coordination system is needed, with respect to emergency support measures, such as the construction of the national energy reserve base, and improved emergency plans to deal with large-scale power emergencies.

Author Contributions: Conceptualization, B.W., L.W. and S.Z.; methodology, B.W., L.W. and S.Z.; validation, B.W.; formal analysis, B.W.; investigation, B.W.; resources, B.W., N.X. and Q.Q.; data curation, B.W., N.X. and Q.Q.; writing—original draft preparation, B.W.; writing—review and editing, B.W., L.W. and S.Z.; supervision, L.W.; project administration, L.W.; funding acquisition, L.W. and S.Z. All authors have read and agreed to the published version of the manuscript.

Funding: This research was funded by the National Natural Science Foundation of China, Grant No. 41971163, 42071281, 71991484, 71991480; The Second Tibetan Plateau Scientific Expedition and Research Program (STEP), Grant No. 2019QZKK1003; Humanities and Social Science Research Project of Hebei Education Department, Grant No. SQ2021081.

Institutional Review Board Statement: Not applicable.

Informed Consent Statement: Not applicable.

Data Availability Statement: Not applicable.

Acknowledgments: We thank Ayman Elshkaki from the Institute of Geographic Sciences and Natural Resources Research, CAS, for providing us with many constructive suggestions to improve the manuscript.

Conflicts of Interest: The authors declare no conflict of interest.

\section{References}

1. Power Rationing. Available online: https://news.cctv.com/2021/09/29/ARTIUF1TOyuNwWF60opflqbM210929.shtml (accessed on 29 September 2021).

2. He, J.K. China's INDC and non-fossil energy development. Adv. Clim. Chang. Res. 2015, 6, 210-215. [CrossRef]

3. Gallagher, K.S.; Zhang, F.; Orvis, R.; Rissman, J.; Liu, Q. Assessing the Policy gaps for achieving China's climate targets in the Paris Agreement. Nat. Commun. 2019, 10, 1256. [CrossRef] [PubMed]

4. Soest, H.; Elzen, M.; Vuuren, D. Net-zero emission targets for major emitting countries consistent with the Paris Agreement. Nat. Commun. 2021, 12, 2140. [CrossRef]

5. Hoag, H. Low-carbon electricity for 2030. Nat. Clim. Chang. 2011, 1, 233-235. [CrossRef]

6. Zou, C.; Xiong, B.; Xue, H.; Zheng, D.W.; Ge, Z.X.; Wang, Y.; Jiang, L.Y.; Pan, S.Q.; Wu, S.T. The role of new energy in carbon neutral. Pet. Explor. Dev. 2021, 48, 480-491. [CrossRef]

7. Deangelo, J.; Azevedo, I.; Bistline, J.; Clarke, L.; Luderer, G.; Byers, E.; Davis, S.J. Energy systems in scenarios at net-zero CO 2 emissions. Nat Commun. 2021, 12, 6096. [CrossRef]

8. Arbabzadeh, M.; Sioshansi, R.; Johnson, J.X.; Keoleian, G.A. The role of energy storage in deep decarbonization of electricity production. Nat Commun. 2019, 10, 1. [CrossRef] 
9. Cherp, A.; Vinichenko, V.; Tosun, J.; Gordon, J.A.; Jewell, J. National growth dynamics of wind and solar power compared to the growth required for global climate targets. Nat. Energy 2021, 6, 742-754. [CrossRef]

10. Grubert, E. Fossil electricity retirement deadlines for a just transition. Science 2020, 370, 1171-1173. [CrossRef]

11. Drechsler, M.; Egerer, J.; Lange, M.; Masurowski, F.; Meyerhoff, J.; Oehlmann, M. Efficient and equitable spatial allocation of renewable power plants at the country scale. Nat. Energy 2017, 6, 17124. [CrossRef]

12. Sixth Energy Plan in Japan. Available online: https: / / baijiahao.baidu.com/s?id=1714329320132461177\&wfr=spider\&for=pc (accessed on 22 October 2021).

13. Fang, K.; Tang, Y.Q.; Zhang, Q.F.; Song, J.N.; Wen, Q.; Sun, H.P.; Ji, C.Y.; Xu, A.Q. Will China peak its energy-related carbon emissions by 2030? Lessons from 30 Chinese provinces. Appl. Energy 2019, 255, 113852. [CrossRef]

14. Tong, D.; Farnham, D.J.; Duan, L.; Zhang, Q.; Lewis, N.S.; Caldeora, K.; Davis, S.J. Geophysical constraints on the reliability of solar and wind power worldwide. Nat. Commun. 2021, 12, 6146. [CrossRef] [PubMed]

15. Veers, P.; Dykes, K.; Lantz, E.; Barth, S.; Bottasso, C.L.; Carlson, O.; Clifton, A.; Green, J.; Green, P.; Holttinen, H.; et al. Grand challenges in the science of wind energy. Science 2019, 366, 443. [CrossRef] [PubMed]

16. Wang, Z.; Zhu, Y.; Zhu, Y.; Shi, Y. Energy structure change and carbon emission trends in China. Energy 2016, 115, 369-377. [CrossRef]

17. Wu, J.; Wang, Z.; Zhu, Q.T.; Gong, Y. Forecast on china's energy consumption and carbon emissions driven by micro innovation. Complex Syst. Complex. Sci. 2016, 13, 68-79.

18. Xu, G.; Schwarz, P.; Yang, H. Adjusting energy consumption structure to achieve China's $\mathrm{CO}_{2}$ emissions peak. Renew. Sustain. Energy Rev. 2020, 122, 109737. [CrossRef]

19. Cui, R.Y.; Hultman, N.; Cui, D.Y.; McJeon, H.; Yu, S.; Edwards, M.R.; Sen, A.; Song, K.H.; Bowman, C.; Clarke, L.; et al. A plant-by-plant strategy for high-ambition coal power phaseout in China. Nat. Commun. 2021, 12, 1. [CrossRef] [PubMed]

20. Zeng, M.; Song, X.; Li, L.Y.; Wang, Y.J.; Yang, W.; Li, Y. China's large-scale power shortages of 2004 and 2011 after the electricity market reforms of 2002: Explanations and differences. Energy Policy 2013, 61, 610-618.

21. Ou, P.; Huang, R.T.; Yao, X. Economic Impacts of Power Shortage. Sustainability 2016, 8, 687. [CrossRef]

22. Thomson, E. Power Shortages in China: Why? China Int. J. 2011, 3, 1.

23. Shi, X.P.; Sun, Y.P.; Shen, Y.F. China's ambitious energy transition plans. Science 2021, 373, 170. [CrossRef] [PubMed]

24. Michal, M.; Philip, A.S. China's power crisis: Long-term goals meet short-term realities. Oies Energy Comment 2021, 39, 1330-1337.

25. $\mathrm{Wu}, \mathrm{J}$. From the formation mechanism of power shortage to analyze the long-term treatment of energy security. China Power Enterp. Manag. 2021, 28, 16-23.

26. Motlagh, S.S.; Panahi, M.; Hemmasi, A.H.; Ghoddousi, J.; Kani, A.R.H.M. A techno-economic and environmental assessment of low-carbon development policies in Iran's thermal power generation sector. Int. J. Environ. Sci. Technol. 2021, 1-16. [CrossRef]

27. Mirjat, N.H.; Uqaili, M.A.; Harijan, K.; Walasai, G.D.; Mondal, M.A.H.; Sahin, H. Long-Term Electricity Demand Forecast and Supply Side Scenarios for Pakistan (2015-2050): A LEAP Model Application for Policy Analysis. Energy 2018, 165, 512-526. [CrossRef]

28. Luis, R.G.; David, B.; Luis, F.M.; Robert, V.C. Long-Term Electricity Supply and Demand Forecast (2018-2040): A LEAP Model Application towards a Sustainable Power Generation System in Ecuador. Sustainability 2019, 11, 5316.

29. Windarta, J.; Purwanggono, B.; Hidayanto, F.; Purwanggono, B.; Fudholi, D.H. Application of LEAP model on long-term electricity demand forecasting in Indonesia, period 2010-2025. In Proceedings of the SHS Web of Conferences, Gdańsk, Poland, 18-20 September 2018; p. 49. [CrossRef]

30. Chen, R.; Rao, Z.H.; Liu, J.X.; Chen, Y.Y.; Liao, S.M. Prediction of energy demand and policy analysis of Changsha based on LEAP Model. Resour. Sci. 2017, 39, 482-489.

31. Guang, F.T. Multi-Dimensional Analysis of the Characteristics and Demand Prediction of China's Electricity Consumption; North China Electric Power University: Baoding, China, 2020.

32. Ma, X.M.; Duan, Y.; Zhou, J.P.; Ji, J.P. Research on the Carbon Mitigation Path of Power Sector in Shenzhen. Ecol. Econ. 2018, 34, 24-29.

33. Huang, J. Scenario analysis of Chinese power demands and uncertainty assessment based on the LEAP Model. Resour. Sci. 2012, 34, 2124-2132.

34. Emergency Warning Notice on Orderly Power Use. Available online: http://fgw.rizhao.gov.cn (accessed on 1 September 2021).

35. State Grid Jilinsheng Power Supply Company. Available online: https://www.bjnews.com.cn/detail/163264136514232.html (accessed on 23 September 2021).

36. Emergency Notice on Orderly Power Utilization. Available online: https:// baijiahao.baidu.com/s?id=1711670018296440938\& wfr $=$ spider\&for $=p c$ (accessed on 23 September 2021).

37. Reasons for Power Rationing in Northeast China. Available online: https://www.thepaper.cn/newsDetail_forward_14688865 (accessed on 27 September 2021).

38. Power Shortage in 2021. Available online: https:/ / shoudian.bjx.com.cn/html/20211125/1190068.shtml (accessed on 25 November 2021).

39. Great Changes in China's Energy in the Throes of "Power Shortage". Available online: https://shupeidian.bjx.com.cn/html/20 211229/1196403.shtml (accessed on 29 December 2021). 
40. Opinions on Fully, Accurately and Comprehensively Implementing the New Development Philosophy to Achieve Carbon Peak and Carbon Neutrality. Available online: http:/ / www.gov.cn/xinwen/2021-10/25/content_5644687.htm (accessed on 25 October 2021).

41. Li, M.J.; Chen, G.P.; Dong, C.; Liang, Z.F.; Wang, W.S.; Fan, G.F. Research on Power Balance of High Proportion Renewable Energy System. Power Syst. Technol. 2019, 43, 3979-3986.

42. Xie, X.R.; He, Z.B.; Mao, H.Y.; Li, H.Z. New issues and classification of power system stability with high shares of renewables and power electronics. Proc. CSEE 2021, 41, 461-475.

43. Li, Q.H.; Wang, C.X. Study on the Major Issues of Renewable Energy Development. Electr. Power 2015, 48, 33-36.

44. Nema, P.; Nema, R.K.; Rangnekar, S. A current and future state of art development of hybrid energy system using wind and PV-solar: A review. Renew. Sustain. Energy Rev. 2009, 13, 2096-2103. [CrossRef]

45. Khare, V.; Nema, S.; Baredar, P. Solar-wind hybrid renewable energy system: A review. Renew. Sustain. Energy Rev. 2006, 58, 23-33. [CrossRef]

46. Xie, S.; Jia, Y.L.; Bai, X.T.; Zhang, Z.H.; Wang, S.Y.; Zheng, X.Y.; Zhao, Y.R. A Review of Tools for Urban Energy Systems Planning and Energy Consumption Analysis. J. Glob. Energy Interconnect 2021, 4, 163-177.

47. LEAP. User Guide of Long Range Energy Alternative Planning System; Stockholm Environment Institute: Boston, MA, USA, 2011.

48. Rahman, M.M.; Paatero, J.V.; Lahdelma, R.; Wahid, M.A. Multicriteria-based decision aiding technique for assessing energy policy elements-demonstration to a case in Bangladesh. Appl. Energy 2016, 164, 237-244. [CrossRef]

49. Perwez, U.; Sohail, A.; Hassan, S.F.; Zia, U. The long-term forecast of Pakistan's electricity supply and demand: An application of long range energy alternatives planning. Energy 2015, 93, 2423-2435. [CrossRef]

50. China's Economy Growth Would Be 5.5\% by 2022. Available online: https:/ / baijiahao.baidu.com/s?id=1722273833748214779\& wfr=spider\&for $=p c$ (accessed on 18 January 2022).

51. Chinese Academy of Social Sciences. Economic Blue Book: Analysis and Forecast of China's Economic Development in 2022; Chinese Academy of Social Sciences: Beijing, China, 2021.

52. Chinese Academy of Social Sciences. Green Paper on Population and Labor: No.19 Report on China's Population and Labor Issues; Chinese Academy of Social Sciences: Beijing, China, 2019.

53. Chinese Academy of Social Sciences. Green Paper on Population and Labor: No.22 Report on China's Population and Labor Issues; Chinese Academy of Social Sciences: Beijing, China, 2022.

54. National Energy Administration. Notice on the Monitoring and Evaluation Results of National Renewable Energy Power Development in 2020; National Energy Administration: Beijing, China, 2021.

55. Yan, R.; Masood, N.A.; Saha TK Bai, F.F.; Gu, H.J. The anatomy of the 2016 South Australia blackout:a catastrophic event in a high renewable network. IEEE Trans. Power Syst. 2018, 33, 5374-5388. [CrossRef]

56. Wang, W.S.; Lin, W.F.; He, G.Q.; Shi, W.H.; Feng, S.L. Enlightenment of 2021 Texas blackout to the renewable energy development in China. Proc. CSEE 2021, 41, 4033-4042.

57. Peter, B.; Alan, T.; Gilbert, B. The quiet revolution of numerical weather prediction. Nature 2015, 525, 47-55.

58. Zhang, Y.Z.; Zhang, N.; Dai, H.C.; Zhang, S.Y.; Wu, X.Y.; Xue, M.M. Model Construction and Pathways of Low-Carbon Transition of China's Power System. Electr. Power 2021, 54, 1-11.

59. Shu, Y.B.; Zhang, L.Y.; Zhang, Y.Z.; Wang, Y.H.; Lu, G.; Yuan, B.; Xia, P. Carbon Peak and Carbon Neutrality Path for China's Power Industry. Strateg. Study CAE 2021, 23, 1-14. [CrossRef]

60. Zhang, X.L.; Liu, J.L.; Wang, K.; Cui, X.Q.; Zou, J. Study on medium and long-term low-carbon development pathway of China's power sector. China Popul. Resour. Environ. 2018, 28, 68-77.

61. Knopf, B.; Kejun, J. Germany and China take the lead. Science 2017, 358, 569. [CrossRef] [PubMed]

62. Shan, B.G. Analysis on the causes of global energy and power shortage in 2021 and its enlightenment to China. China Energy News 2022, 2, 12.

63. Bruninx, K.; Delarue, E. A Statistical Description of the Error on Wind Power Forecasts for Probabilistic Reserve Sizing. IEEE Trans. Sustain. Energy 2014, 5, 995-1002. [CrossRef]

64. Xue, C.; Ren, J.; Ma, X.W.; Cui, W.; Liu, Y.B.; Wang, X.D. Mechanism of peak regulation auxiliary electricity market in the presence of high-penetration renewable energy and its practice in northwest China. Electr. Power 2020, 54, 19-28.

65. Wang, J.; Redondo, N.E.; Galiana, F.D. Demand-side reserve offers in joint energy/reserve electricity markets. IEEE Trans. Power Syst. 2003, 18, 1300-1306. [CrossRef]

66. Liu, Z.; Deng, Z.; He, G.; Wang, H.L.; Zhang, X.; Lin, J.; Qi, Y.; Liang, X. Challenges and opportunities for carbon neutrality in China. Nat. Rev. Earth Environ 2021, 3, 141-155. [CrossRef]

67. Wood Mackenzie. Sprint or Marathon? China Provincial Renewable Power, Competitiveness Report; Wood Mackenzie Consulting Co., Ltd.: Beijing, China, 2019.

68. Li, J.F.; Jiang, S.Y. Analysis on energy security in the Transition Era and China's plan. Energy China 2020, 42, 4-10.

69. National Development and Reform Commission. The National Development and Reform Commission in China; National Development and Reform Commission: Beijing, China, 2021.

70. NDRC Energy Research Institute. China's Photovoltaic Development Outlook in 2050; NDRC Energy Research Institute: Beijing, China, 2019 
71. Wang, X.C.; Jin, Y.M.; Zhang, J.F.; Yang, B. A Comprehensive Evaluation Model for Power System with Large-Scale New Energy Considering Regional Differences. Electr. Power 2018, 51, 178-184.

72. Shu, Y.B.; Zhang, Z.G.; Guo, J.B.; Zhang, Z.L. Study on Key Factors and Solution of Renewable Energy Accommodation. Proc. CSEE 2017, 37, 1-8.

73. Ren, J.; Xue, C.; Ma, X.W.; Liu, Y.B.; Wang, X.D. Two-stage Model of Peak Regulation Ancillary Service Market with Source-Load Interaction. Autom. Electr. Power Syst. 2021, 45, 94-102.

74. Shu, Y.B.; Chen, G.P.; He, J.B.; Zhang, F. Building a New Electric Power System based on New Energy Sources. Strateg. Study CAE 2021, 23, 61-69. [CrossRef]

75. China Electricity Council. Research on Flexible Operation Policy of Coal Motor Unit; China Electricity Council: Beijing, China, 2019.

76. Xin, H.; Liu, Y.; Wang, Z.; Gan, D.Q.; Yang, T.C. A New Frequency Regulation Strategy for Photovoltaic Systems without Energy Storage. IEEE Trans. Sustain. Energy 2013, 4, 985-993. [CrossRef]

77. Delille, G.; Francois, B.; Malarange, G. Dynamic frequency control support by energy storage to reduce the impact of wind and solar generation on isolated power system's inertia. IEEE Trans. Sustain. Energy 2012, 3, 931-939. [CrossRef]

78. Li, H.; Liu, D.; Yao, D.Y. Analysis and Reflection on the Development of Power System towards the Goal of Carbon Emission Peak and Carbon Neutrality. Proc. CSEE 2021, 41, 6245-6259. 